\title{
CHEMOSPHERE
}

\section{Treatment of landfill leachate by ozone-based advanced oxidation processes}

\author{
Jerry J. Wu ${ }^{\text {a,* }}$, Chih-Chao Wu ${ }^{\text {a }}$, Hong-Wen Ma ${ }^{\mathrm{b}}$, Chia-Chi Chang ${ }^{\mathrm{a}}$ \\ ${ }^{a}$ Department of Environmental Engineering and Science, Feng Chia University, Taichung 407, Taiwan \\ ${ }^{\mathrm{b}}$ Graduate Institute of Environmental Engineering, National Taiwan University, Taipei, Taiwan
}

Received 17 July 2002; received in revised form 7 October 2003; accepted 7 October 2003

\begin{abstract}
In this study, laboratory experiments are conducted to compare the efficacy using several ozone-based advanced oxidation processes (AOPs), such as $\mathrm{O}_{3}, \mathrm{O}_{3} / \mathrm{H}_{2} \mathrm{O}_{2}$, and $\mathrm{O}_{3} / \mathrm{UV}$, to treat landfill leachate. Raw leachate was initially coagulated by ferric chloride $\left(\mathrm{FeCl}_{3}\right)$ at the experimental-determined optimal dosage of $900 \mathrm{mgl}{ }^{-1}$, and the ozone-based AOPs were subsequently applied. Results indicate that all AOPs would result in a significant increase on the ratio of $\mathrm{BOD}_{5} / \mathrm{COD}$ from 0.06 to 0.5 at the applied ozone dosage of $1.2 \mathrm{gl}^{-1}$. The increase on biodegradability for ozonated leachate indicates that these AOPs would be beneficial to the subsequent biological treatment process. To better explain the alteration of high organic molecules after oxidation, ultrafiltration was used to separate the leachate by several molecular weight cutoffs (MWCO). The COD distribution for coagulated leachate is $34 \%$ for MWCO $>10 \mathrm{kDa}, 7 \%$ for MWCO between 5 and $10 \mathrm{kDa}, 22 \%$ for MWCO between 1 and $5 \mathrm{kDa}$, and $37 \%$ for MWCO $<1 \mathrm{kDa}$. Following ozonation or AOPs, the predominant distribution of COD would be obviously shifted to the MWCO less than 1000 $\mathrm{g} \mathrm{mol}^{-1}(72-85 \%)$ over the other MWCO ranges. In addition, Gel Permeation Chromatograph (GPC) analysis has showed a substantial agreement on the cleavage of larger organic compounds into smaller ones. $\mathrm{O}_{3} / \mathrm{UV}$ was found to be the most effective approach among these ozone-based AOPs to enhancing the biodegradability and eliminating the color of leachate.
\end{abstract}

(c) 2003 Elsevier Ltd. All rights reserved.

Keywords: Ozone-based advanced oxidation processes; Landfill leachate; Biodegradability; Gel permeate chromatography; ADMI; Fourier transformed infrared

\section{Introduction}

The fact for the serious contamination into the receiving water by the effluent of landfill leachate has increasingly attracted more concerns worldwide. Fortunately, the remarkable growth in economics and living standard has accelerated the development of water and wastewater purification technology. It is well acknowledged by the

\footnotetext{
${ }^{*}$ Corresponding author. Tel.: +886-4-24517250; fax: +886-424517686.

E-mail address: jjwu@fcu.edu.tw (J.J. Wu).
}

fact that landfill leachate released by municipal wastes contains large quantities of non-biodegradable and toxic constituents including organic and inorganic substances and that several treatment steps must be adopted to achieve a satisfactory removal of hazardous pollutants. Landfill leachate is commonly generated as a result of water from precipitation, surface run-off, and infiltration or intrusion of groundwater percolating through the landfill (Tsai et al., 1997; Ince, 1998; öman and Rosqvist, 1999). Leachate characteristics are determined by the sitting, the design and the means of operation of the landfill, and also depend on the condition of waste biodegradation through time. It is rather complicated that contaminants in the landfill leachate are released from the waste due to 
successive biological, chemical, and physical processes. Baig et al. (1999) classified landfill leachate into three types, such as young, intermediate, and stabilized, according to its different landfill ages.

Conventionally, Landfill leachate is treated by the biological processes to eliminate its organic loading in the effluent. Aerobic and anaerobic biological processes have been reported to remove a substantial fraction of biological oxygen demand (BOD), chemical oxygen demand (COD) and ammonia from old solid-waste landfill leachate (Dzombak et al., 1990). Although Nedwell and Reynolds (1996) indicated that the use of two-stage anaerobic processes involving methanogenic and sulfurreducing digestions results in a steady state removal efficiency of COD up to $97 \%$, the most difficult aspects for the old landfill site is the degradation of those recalcitrant organic compounds within a reasonable period by bio-treatment. In the past decade, advanced oxidation technologies including ozonation have been proposed and suggested as an auxiliary approach or alternative for the management of landfill leachate (Bigot et al., 1995). Although many of the previous researches using ozone or advanced oxidation processes (AOPs) have demonstrated the effectiveness in eliminating COD or total organic carbon (TOC) for the landfill leachate (Wable et al., 1993; Bigot et al., 1994; Kim et al., 1997; Steensen, 1997; Wenzel et al., 1999), most of them only used AOPs on the final stabilization prior to discharging into the receiving water body. Therefore, in this study we have attempted using ozone-based AOPs as pretreatment to decompose the recalcitrant organic matters and increase their biodegradation for the subsequent bio-associated treatment. Therefore, the objectives in this paper could be summarized as (1) to evaluate the feasibility of preoxidation of ozone-based AOPs to increase the biodegradability and (2) to compare the efficacy of different ozone-based AOPs on oxidizing the organic compounds.

\section{Materials and methods}

\subsection{Leachate collection and characteristics}

Raw leachate was collected from the wastewater treatment plant of Chen-Shi-Li municipal landfill located close to Tainan city in southern Taiwan. Upon collection, the leachate was stored at $4{ }^{\circ} \mathrm{C}$ to minimize any further change that might occur in its physicochemical and biological properties until the experiments and analyses were carried out within a week. The physicochemical characteristics of the raw leachate used in our study were analyzed and listed in Table 1. According to the characteristics of $\mathrm{pH}$ and biodegradability in the collected raw leachate, it is apparent that the raw leachate would fall into the category of stabi-
Table 1

Characteristics analysis of raw landfill leachate used in this study

\begin{tabular}{ll}
\hline Parameter & Mean value or concentration \\
\hline $\mathrm{pH}$ & $8.1^{\mathrm{a}}$ \\
$\mathrm{COD}$ & $6500 \mathrm{mgl}^{-1}$ \\
$\mathrm{TOC}$ & $4000 \mathrm{mg} \mathrm{l}^{-1}$ \\
$\mathrm{BOD}_{5}$ & $500 \mathrm{mgl}^{-1}$ \\
$\mathrm{NH}_{3}-\mathrm{N}$ & $5500 \mathrm{mgl}^{-1}$ \\
$\mathrm{Cl}^{-}$ & $6000 \mathrm{mg} \mathrm{l}^{-1}$ \\
Alkalinity & $650 \mathrm{mgl}^{-1}$ as CaCO \\
True color & $12000 \mathrm{ADMI}^{\mathrm{b}}$ \\
\hline
\end{tabular}

${ }^{\mathrm{a}}$ The median value.

${ }^{\mathrm{b}}$ American Dye Manufacturers Institute.

lized form as it has higher $\mathrm{pH}$ value (>7.5) and lower $\mathrm{BOD}_{5} / \mathrm{COD}(<0.1)$ due to the slow release of refractory organic matter from the landfill site.

\subsection{Ozone and AOPs experiments}

Ozone was generated from dried pure oxygen by corona discharge using an ozone generator (Ozonia RXO-5), which can produce $6 \%$ ozone concentration $(\mathrm{w} / \mathrm{w})$ in the oxygen enriched gas stream. To better maintain the performance of the ozone system, the oxygen was dried using a molecular sieve before entering into the ozone generator. A 4-1 semi-batch reactor, which was made of pyrex glass with the dimensions of $12 \mathrm{~cm}$ diameter and $50 \mathrm{~cm}$ tall, was used to facilitate the operation of all ozone-based oxidation processes (Fig. 1). Ozone was introduced through a porous fritted diffuser that can produce fairly fine bubbles with diameter less than $1 \mathrm{~mm}$, which had been determined using camera with close-up lens and image analysis software Matrox Inspector 2.0 (Chang, 2001). The gas flowrate was regulated at $11 \mathrm{~min}^{-1}$ by a mass flow controller (Brooks 5850E). The gaseous ozone concentrations in the inlet and outlet stream were determined spectrophotometrically by the absorbance of ozone measured in a 2-mm flow-through quartz cuvette at the wavelength $258 \mathrm{~nm}$. An extinction coefficient of $3000 \mathrm{M}^{-1} \mathrm{~cm}^{-1}$ was used to convert absorbances into concentration units (Nowell and Hoigné, 1988). The inlet and outlet gaseous ozone concentrations in this study were calculated as 40 and $0 \mathrm{mgl}^{-1}$, respectively. Since ozone dosage is typically defined as the product of gas flowrate, ozone concentration, and ozonation period, divided by the reactor volume, the desired dosage of $1.2 \mathrm{gl}^{-1}$ would take $30 \mathrm{~min}$ to achieve. To reduce foaming caused by the bubbling of ozone into the leachate, $5 \mathrm{ml}$ of antifoaming agent, Anti-foam 289 (Sigma Co.) was added to the leachate prior to ozonation. All experiments were operated at $25{ }^{\circ} \mathrm{C}$ using a water jacket around the reactor. During the experimental period, the leachate in 


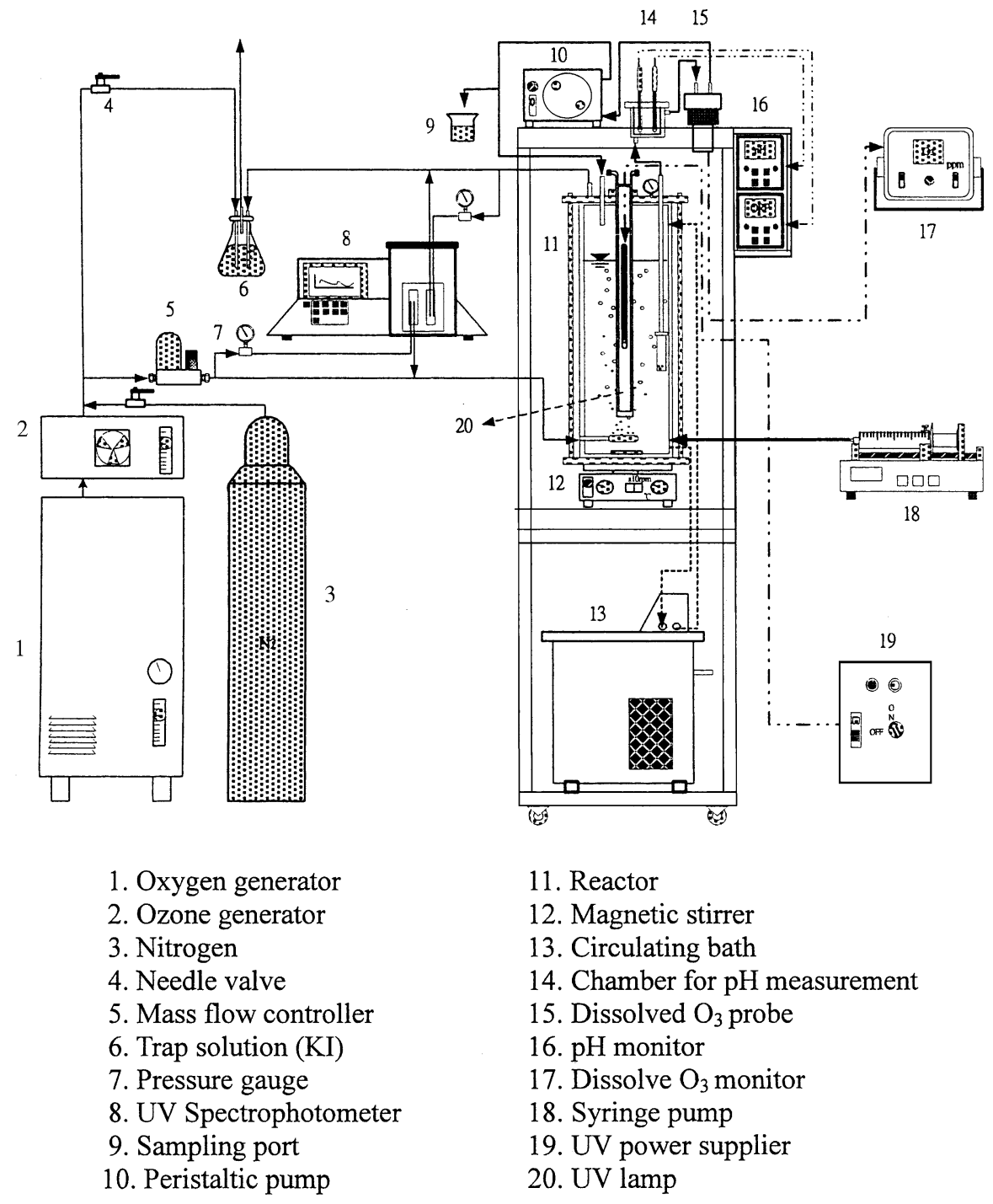

Fig. 1. System setup for ozone-based advanced oxidation processes.

the reactor was pumped continuously through a closed loop equipped with a chamber where all sensors of $\mathrm{pH}$ and dissolved ozone monitor were placed and with a sampling port where the leachate could be withdrawn for chemical analyses. The hydrogen peroxide (30\%) injection system was initiated using a syringe pump to deliver a fixed flowrate, depending on the ratio to the applied ozone dosage, into the reactor. The input ratio of $\mathrm{H}_{2} \mathrm{O}_{2}$ to ozone by weight was controlled at $1.0 \mathrm{~g} \mathrm{~g}^{-1}$, which had been previously determined to be the optimal ratio (Chang, 2001). In addition, a high-pressure mercury UV lamp (Hanovia Co.) with an input energy of $200 \mathrm{~W}$ and output intensity of $5.1 \mathrm{~mW} \mathrm{~cm}^{-2}$ was placed at the center of the reactor and shielded by a vertically immersed quartz jacket which was circulated with cold water to avoid heat accumulation. A black box placed outside the reactor was employed to minimize any penetration of UV light when UV-enhanced facility was operated.

\subsection{Analytical methods}

The characteristic analyses of the raw and oxidized leachate including $\mathrm{BOD}_{5}, \mathrm{COD}$, and ammonia nitrogen, were performed according to Standard Methods (APHA, 1998). Chloride ions and TOC were measured using ion chromatography (Dionex, DX-100) and TOC analyzer (Tekmar Dohrmann, Apollo 9000), respectively. Color was determined according to the ADMI method proposed by American Dye Manufactures Institute using 
three different wavelengths, including 438, 540, and 590 $\mathrm{nm}$. To better understand the change of molecular weight distribution after oxidation, both gel permeation chromatograph (GPC) and ultrafiltration membrane separation were employed. GPC was performed using a HPLC system (Shimadzu LC-10) and a refractive-index detector. The TSKgel G3000PW $\mathrm{XL}_{\mathrm{XL}}$ column (TOSOH Co.), which is especially suitable for the analysis of molecular weight within the range of $1-8.5 \mathrm{kDa}$, was used to separate the organics in the leachate into several groups. The pump flowrate was set at $0.6 \mathrm{ml} \mathrm{min}{ }^{-1}$. The average molecular weight determined by GPC chromatography could be expressed as below (Dickenson and Amy, 2000).

$$
\begin{aligned}
& M_{n}=\sum C_{i} M_{i} / C_{i} \\
& M_{w}=\sum C_{i} M_{i}^{2} / \sum C_{i} M_{i} \\
& D=M_{w} / M_{n}
\end{aligned}
$$

where $M_{n}$ is the average molecular weight based on the calculation by molecule number; $M_{w}$ is the average molecular weight based on the calculation by weight composition of molecules; $C_{i}$ is the area or number of specific molecular weight $\left(M_{i}\right)$ from GPC chromatography; $M_{i}$ is the molecular weight; $D$ is the distribution coefficient of average molecular weight and $D \geqq 1$. The UF system (Amicon Co.) was utilized to separate organics by passing leachate sample through the ultracel PL membranes with several molecular weight cutoffs (MWCO) of 1, 5, and $10 \mathrm{kDa}$. Furthermore, the fourier transform infrared spectroscopy (FTIR-8201, Shimadzu Co.) was also used to characterize and observe the change of functional groups in the leachate.

\section{Results and discussion}

\subsection{Coagulation by ferric chloride}

Raw leachate collected from the landfill site was initially coagulated by ferric chloride before all ozonebased advanced oxidation processes were applied. According to the evaluation of jar tests in the laboratory, the most optimal coagulant dosage for COD removal of the raw leachate was determined to be 900 $\mathrm{mgl}^{-1}$. Under this circumstance the total COD decreased approximately $60 \%$ (from 6500 to $2500 \mathrm{mg}^{-1}$ ). Similarly, the significant change on the percentage distributions of COD at different MWCOs was observed from $53 \%$ to $34 \%$ for the molecular weight range greater than $10 \mathrm{kDa}$ (Fig. 2), indicating that coagulation mechanism would result in the substantial removal of larger organic molecules. The average molecular weight $\left(M_{w}\right)$ based upon the calculation of its weight composition in GPC chromatography was also found to de- crease significantly from 75 to $11 \mathrm{kDa}$. It appears that larger molecule portions of raw leachate can be effectively removed by ferric chloride coagulation. However, the ratio of $\mathrm{BOD}_{5} / \mathrm{COD}$, a traditional indicator of biodegradability, of the leachate after coagulation is still below 0.1 . It can be predicted that the difficulty would take place if the subsequent biological treatment process is directly applied to decompose these residual organic matters in the effluent of coagulation treatment. Therefore, the ozone-based oxidation processes is proposed in the following session on highlighting the enhancement of biodegradability of landfill leachate and removal of color.

\subsection{Ozone-based advanced oxidation processes}

In this study, three kinds of oxidation processes including ozone, ozone/UV, and ozone/hydrogen peroxide were provided to treat the landfill leachate after coagulation. It is apparent that all of the ratios of $\mathrm{BOD}_{5}$ to COD in Fig. 3(a) were observed to increase from 0.1 to 0.5 during the period of applying $1.2 \mathrm{~g} \mathrm{l}^{-1}$ ozone dosage regardless of the combination with UV or hydrogen peroxide. This result indicates that the biodegradability of the leachate has been substantially improved after oxidation reaction. Nevertheless, ozone/UV could be figured out to have a better oxidation ability at the initial oxidation period by comparing with the other two processes in Fig. 3(a). The hydroxyl radicals, induced from the decomposition of ozone or either from the initiation of hydrogen peroxide or UV lamp, are unable to further accelerate the degradation of nonbiodegradable organics primarily due to the presence of greater alkalinity, such as bicarbonate and carbonate, acting as the $\mathrm{OH}$ radical scavenger (Langlais et al., 1991; Masten et al., 1996) in the leachate. Moreover, the effect of $\mathrm{pH}$ values was found to increase approximately from 8.1 to 8.6 for all ozone-based AOPs used in this study. The increase in $\mathrm{pH}$ upon sparging with ozone is thought to be due to the stripping of carbon dioxide and volatile fatty acids (Wu et al., 1998a).

Considering the influence of oxidation on molecular weight distribution, Fig. 2 using UF separation shows that COD distribution of the coagulated leachate is $34 \%$ for MWCO $>10 \mathrm{kDa}, 7 \%$ for MWCO between 5 and 10 $\mathrm{kDa}, 22 \%$ for MWCO between 1 and $5 \mathrm{kDa}$, and $37 \%$ for $\mathrm{MWCO}<1 \mathrm{kDa}$. After applying ozonation process alone, the predominant COD distribution would be significantly shifted to the MWCO less than $1 \mathrm{kDa}$ $(72 \%)$, which appears that the organic compounds with larger molecular weight has been oxidized into smaller ones. As such, ozone/UV behaves much further destruction for the large organic compounds into small pieces with the $85 \%$ portion in COD distribution less than $1 \mathrm{kDa}$. Similarly, the use of GPC separation also gives a clear evidence (Table 2 ) that average molecular weight 
Raw Leachate

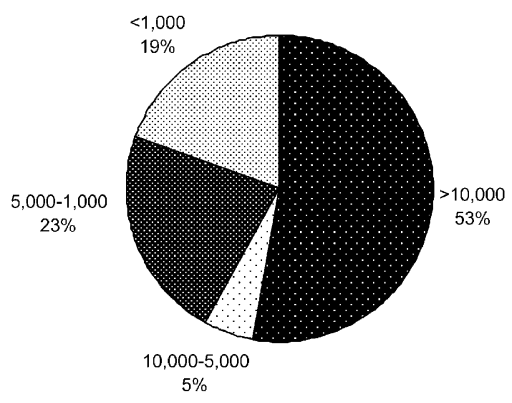

Ozonated Leachate

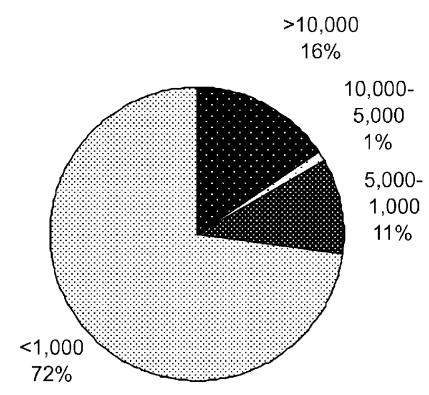

Coagulated Leachate

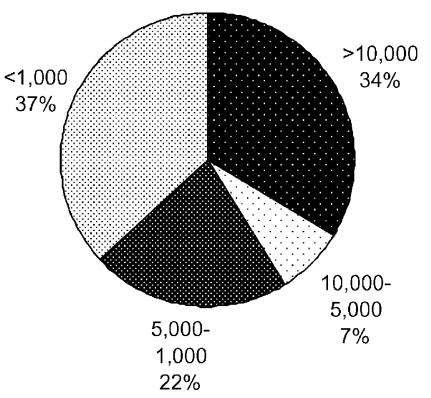

Ozone/UV Leachate

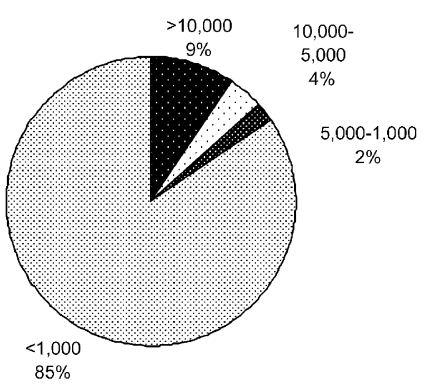

Fig. 2. Percentage distribution of COD on leachate using UF separation at different MWCOs.

$\left(M_{w}\right)$ of the organic compounds in the leachate decreases from $10800 \mathrm{~g} \mathrm{~mol}^{-1}$ to $7170 \mathrm{~g} \mathrm{~mol}^{-1}$ by ozonation alone, to $7800 \mathrm{~g} \mathrm{~mol}^{-1}$ by ozone/UV, and to $6080 \mathrm{~g} \mathrm{~mol}^{-1}$ by ozone/hydrogen peroxide. Another critical parameter, distribution coefficient defined by $D=M_{w} / M_{n}$, was used to assess the distribution range of molecular weights. The larger $D$ value means more broaden distribution of molecular weights would be perceived. Table 2 indicates the $d$ value was observed to decrease from 3.4 to 2.2 by the ozone-based oxidation processes. Thus, the trend of becoming into smaller molecules from larger organic compound by chemical oxidation processes would be closely related to the enhancement of biodegradability. Vogel et al. (2000) presented a useful parameter for characterizing oxidation process by using the mean oxidation number of carbon (MOC):

$\mathrm{MOC}_{s}=4-1.5(\mathrm{COD} / \mathrm{TOC})$

The changes of MOC during the course of oxidation reaction were observed in Fig. 3(b). Ozone/UV leads to the most rapid increase in the oxidation state of carbonaceous compounds than the other two processes. It is essentially consistent to the observation for the change of $\mathrm{BOD}_{5} / \mathrm{COD}$. Nevertheless, the oxidation states finally achieve a stable level after ozone dosage greater than 0.6 $\mathrm{gl}^{-1}$ for all of three oxidation approaches.
For the removal of organic parameters such as TOC, it can be found in Fig. 3(c) that ozonation process alone has the least efficiency in reducing TOC (15\% removal), which can be attributed to the destruction mechanisms partially governed by direct reaction of ozone molecules, which are known to react slowly and to end up in carboxylic acids, aldehydes, and ketones, rather than $\mathrm{CO}_{2}$. Although the ozone process alone has the ability to produce hydroxyl radicals via the decomposition pathway of radical-type chained reactions (Langlais et al., 1991), the net production efficiency of free radicals is still less than the other ozone-based AOPs used in this research. Since the ozone-based AOPs could not decompose appreciable amount of organic components in the leachate at the ozone dosage used in this experiment, a biological process would be recommended to operate after the oxidation treatment by degrading the residual organic intermediates into final stable products, such as carbon dioxide and water. Typically, color of leachate is another environmentally concerned issue. As ozone has been widely utilized as a reliable technique and alternative for decolorizing effluent of the dyeing industry (Wu et al., 1998b), the removal of color of leachate is also included in this session. Color of leachate has been measured to decrease significantly with the increase of ozone dosage as seen in Fig. 3(d). Since most colors are 


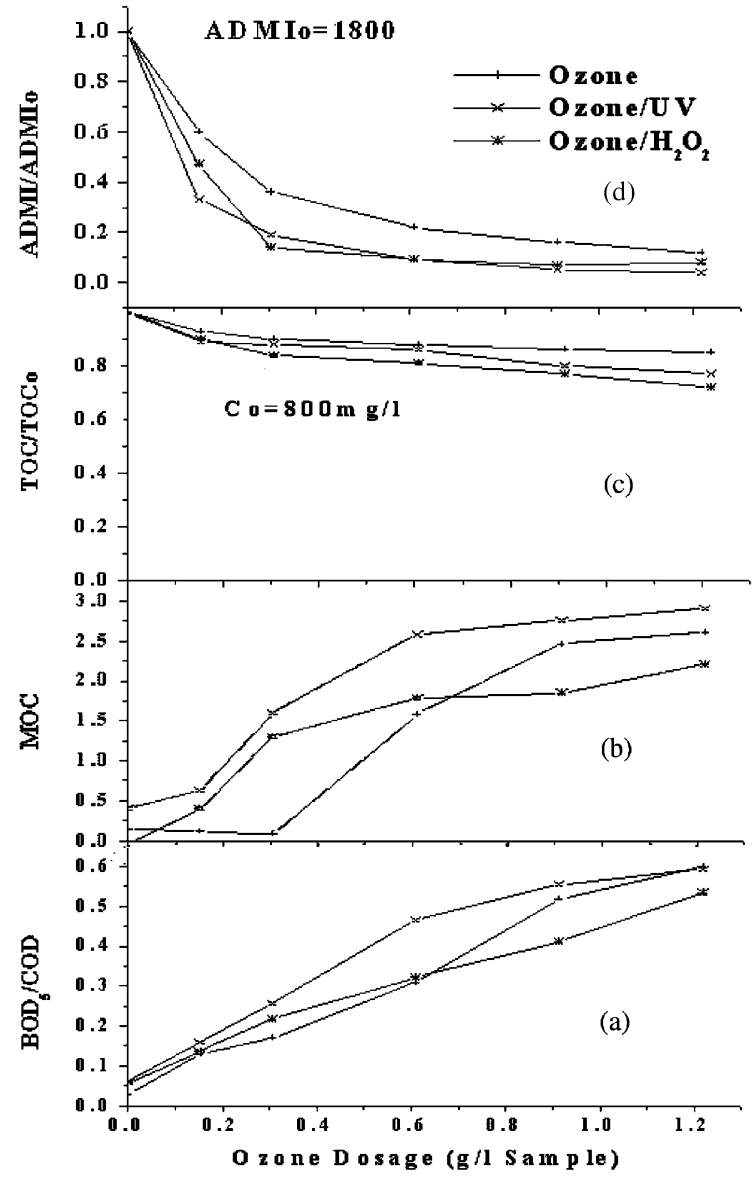

Fig. 3. (a) $\mathrm{BOD}_{5} / \mathrm{COD}$ change, (b) MOC change, (c) percentage change of TOC, and (d) percentage change of color (ADMI) of leachate at different ozone-base AOPs and ozone dosage.

Table 2

Calculation of average molecular weight on GPC separation

\begin{tabular}{llrl}
\hline & $M_{n}$ & \multicolumn{1}{c}{$M_{w}$} & $d\left(M_{w} / M_{n}\right)$ \\
\hline After coagulation & 3190 & 10800 & 3.4 \\
$\mathrm{O}_{3}$ & 3070 & 7170 & 2.4 \\
$\mathrm{O}_{3} / \mathrm{UV}$ & 3010 & 7800 & 2.6 \\
$\mathrm{H}_{2} \mathrm{O}_{2} / \mathrm{O}_{3}$ & 2810 & 6080 & 2.2 \\
\hline
\end{tabular}

mainly originated from the unsaturated bonds and specific functional groups, ozone and hydroxyl radicals would be very attractive on specifically attacking the conjugated chains that impart color to the organic molecules.

Fourier transform infrared spectroscopy (FTIR) has been frequently utilized in characterizing the functional groups of the organics for many environmental analyses. In Fig. 4, it is apparent that the hydroxyl group intensity

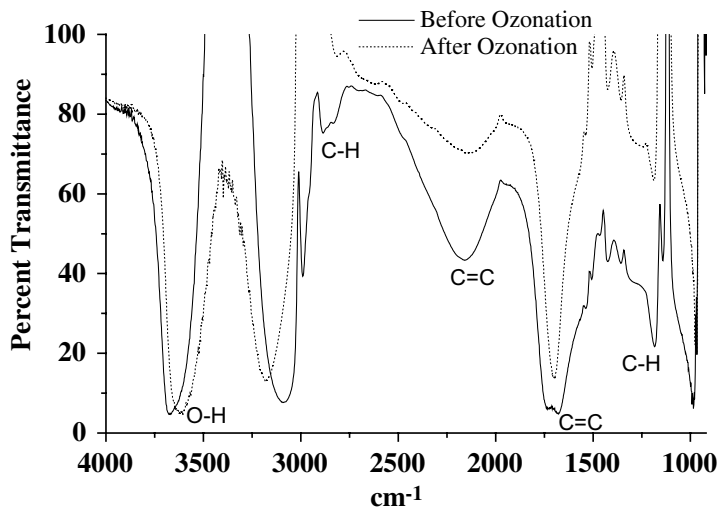

Fig. 4. FTIR spectra of leachate before and after ozonation process.

increases after ozone oxidation, which results in the substitution of functional groups of the organic intermediates associated with the electrophilic reaction by adding into the oxygen atoms. In contrast, the intensity representing the specific stretch wavenumbers of double or triple bond between carbons has been observed to diminish after ozonation mainly due to the mechanism of cyclo addition (Langlais et al., 1991).

\section{Conclusion}

This research can lead to several conclusions summarized as below:

1. Coagulation pretreatment can effectively remove varieties of large molecules in the raw landfill leachate and aid on the subsequent treatment of ozonebased advanced oxidation processes.

2. Biodegradability indicated by $\mathrm{BOD}_{5} / \mathrm{COD}$ of landfill leachate can be significantly enhanced when applied ozone dosage till $1.2 \mathrm{gl}^{-1}$. Ozone/UV is found to be the best oxidation approach among the three types of selected processes. Leachate separated by UF membrane and GPC has demonstrated the composition shifting from larger molecules into smaller ones. Thus, it is thought to have a direct relationship with the increase of leachate biodegradability.

3. The ozone-based advanced processes are demonstrated to decolorize the leachate for $90 \%$ removal. Nevertheless, the removal of TOC is potentially limited even though rather high dosage of ozone is applied. This result implies that ozone-based AOPs should be an excellent alternative prior to using biological treatment process.

4. The FTIR analysis provides useful information in characterizing the change of functional groups of leachate after ozonation reaction. 


\section{Acknowledgements}

The authors wish to thank the National Science Council of the Republic of China for the financial support.

\section{References}

APHA, 1998. Standard Methods for the Examination of Water and Wastewater, 20th ed. Washington.

Baig, S., Coulomb, I., Courant, P., Liechti, P., 1999. Treatment of landfill leachates: Lapeyrouse and Satrod case studies. Ozone Sci. Eng. 21, 1-22.

Bigot, V., Luck, F., Paillard, H., Wagner, A., 1994. Landfill leachate treatment: comparison of three oxidation processes using ozone. In: Proceeding IOA Regional Conference, Zurich, Switzerland, pp. 219-228.

Bigot, V., Luck, F., Paillard, H., Wagner, A., 1995. Landfill leachate treatment: comparison of three oxidation processes using ozone. In: Proceeding IOA Regional Conference, Zurich, Switzerland, pp. 219-228.

Chang, C.C., 2001. The Use of Ozone and Ozone-based AOPs to Treat Landfill Leachate, Master Thesis, Feng Chia University.

Dickenson, E.R.V., Amy, G.L., 2000. Natural organic matter characterization of clarified waters subjected to advanced bench-scale treatment processes. In: Barrett, S.E., Kransner, S.W., Amy, G.L. (Eds.), Natural Organic Matter and Disinfection By-Products, Characterization and Control in Drinking Water. American Chemical Society, Washington, DC, pp. 122-138.

Dzombak, D.A., Lagnese, K.M., Spengel, D.B., Luthy, R.G., 1990. Comparison of activated sludge and RBC treatment of leachate from a solid waste landfill. In: Proc. Spec. Conf. Water Qual. Manage. Landfills, Water Pollut. Fed., Alexandria, Virginia, 4.39.

Ince, N.H., 1998. Light-enhanced chemical oxidation for tertiary treatment of municipal landfill leachate. Water Environ. Res. 70, 1161-1169.

Kim, S.M., Geissen, S.U., Vogelpohl, A., 1997. Landfill leachate treatment by a photoassisted Fenton reaction. Water Sci. Tech. 35, 239-248.
Langlais, B., Reckhow, D.A., Brink, D.R., 1991. Ozone in Water Treatment-Application and Engineering. Lewis Publishers, Michigan.

Masten, S.J., Galbraith, M.J., Davies, S.H., 1996. Oxidation of trichlorobenzene using advanced oxidation processes. Ozone Sci. Eng. 18, 535-548.

Nedwell, D.B., Reynolds, P.J., 1996. Treatment of landfill leachate by methanogenic and sulphate reducing digestion. Water Res. 30, 21-28.

Nowell, L.H., Hoigné, J., 1988. Interaction of iron (II) and other transition metals with aqueous ozone. In: Proceeding of the 8th Ozone World Congress, IOA, Zurich, Switzerland, pp. E80-E95.

öman, C., Rosqvist, H., 1999. Transport fate of organic compounds with water through landfills. Water Res. 33, 2247-2254.

Steensen, M., 1997. Chemical oxidation for the treatment of leachate: process comparison and results from full-scale plants. Water Sci. Tech. 35, 249-256.

Tsai, C.T., Lin, S.T., Shue, Y.C., Su, P.L., 1997. Electrolysis of soluble organic matter in leachate from landfills. Water Res. 31, 3073-3081.

Vogel, F., Harf, J., Hug, A., Rudolf von Rohr, P., 2000. The mean oxidation number of carbon(MOC) - a useful concept for describing oxidation processes. Water Res. 34, 26892702.

Wable, O., Jousset, M., Courant, P., Duguet, J.P., 1993. Oxidation of landfill leachates by ozone and hydrogen peroxide: a French example. In: Proceeding International Symposium on Ozone-Oxidation Methods for Water and Wastewater Treatment, IOA.

Wenzel, A., Gahr, A., Niessner, R., 1999. TOC-removal and degradation of pollutants in leachate using a thin-film photoreactor. Water Res. 33, 937-946.

Wu, J.J., Park, S.H., Hengemuehle, S.M., Yokoyama, M.T., Person, H.L., Masten, S.J., 1998a. The effect of storage and ozonation on the physical, chemical, and biological characteristics of swine manure slurries. Ozone Sci. Eng. 20, 3550 .

Wu, J., Euteman, M.A., Law, S.E., 1998b. Evaluation of membrane filtration and ozonation processes for treatment of reactive-dye wastewater. J. Environ. Eng.-ASCE 3, 227-272. 